\title{
A project identifying potential risk factors leading to diabetic ketoacidosis in patients with type 1 diabetes treated with an insulin pump
}

\section{DOI: 10.7861/clinmed.2019-0495}

Diabetic ketoacidosis (DKA) is a life threatening condition in people with type 1 diabetes (T1D). ${ }^{1}$ With $10-30 \%$ of people in developed countries on insulin pump therapy for managing T1D, DKA in such patients can result in fatal or near-fatal consequences. $^{2-4}$ Despite its severity, there is no reporting process for its frequency in those on pump therapy, thus we have undertaken an audit to analyse potential risk factors leading to DKA admissions. The aim was to retrospectively review a cohort of adult T1D patients established on an insulin pump (for a minimum of 4 years), who had been admitted with DKA in the preceding 3 years (2017-2019). Key clinical features such as the patients' glycated haemoglobin ( $\mathrm{HbA1c}$ ) prior to admission and the time since last being seen in clinic were analysed, alongside metabolic parameters, to try and pinpoint critical warning signs to indicate increased risk of DKA in these individuals. Data collection also incorporated variables on admission including glucose levels, $\mathrm{pH}$ and ketones. Episodes of DKA arising from 11 patients were analysed (some patients had multiple episodes). In the episodes for which full data were available, the overall mean lowest $\mathrm{pH}$ during admission was 7.23. The median time since the patients' last visit to the clinic was 4.5 months. We compared the clinical data during the index admission of these patients seen before and after 4.5 months, in Table 1, showing increased severity in those with a longer duration from the last clinic. Potential causes of DKA included infection, pump failure and other pathologies. There were several strong positive correlations found: the last $\mathrm{HbA1} \mathrm{c}$ measurement and the time since the last visit to the clinic ( $r=0.597)$, the number of missed clinic visits in the study period and the maximum ketones on admission $(r=0.654)$, the last $\mathrm{HbA} 1 \mathrm{c}$ measurement and the maximum ketones during admission $(r=0.666)$. Comparison of the most recent HbA1c in the DKA cohort $(82.9 \mathrm{mmol} / \mathrm{mol}$ ) versus an equivalent pump cohort who did not experience DKA $(60.5 \mathrm{mmol} / \mathrm{mol})$, showed there was a significant difference using a Mann-Whitney $U$ test $(p<0.05)$.

\section{Discussion}

Our data show that a significant number of DKA episodes occurred in patients established on insulin pumps. Within this group, $\mathrm{HbA} 1 \mathrm{c}$ levels were, on average, very high and higher
Table 1. Metabolic and clinical data in pump

patients admitted with diabetic ketoacidosis

Mean time on insulin pump, years

Mean age, years

34.44

Mean length of stay, days

Mean lowest pH during admission (7.35-7.45)

if clinic was $<4.5$ months ago

if clinic was $>4.5$ months ago

Mean highest ketones during admission $(<0.6 \mathrm{mmol} / \mathrm{L}), \mathrm{mmol} / \mathrm{L}$

if clinic was $<4.5$ months ago

if clinic was $>4.5$ months ago

than the pump cohort in general. We can also conclude that, as suggested by the several strong positive correlations, not attending clinics or having less frequent contact with the diabetes team could be linked to severity in some DKA admissions.

These data show that more focused management for patients established on pumps with highly elevated $\mathrm{HbA} 1 \mathrm{c}$, in addition to clearer future planning for reviewing pump therapy (including so-called 'pump holidays'), could be required. The presence of risk factors for DKA in insulin pump users illustrates that with an increasing number of such patients, including those in hospital, detailed multidisciplinary review systems must be embedded to optimise clinical outcomes. ${ }^{5}$

CHANTELLE M CAINES

Medical student, University of Cambridge, Cambridge, UK ABIGAIL SHAW

Government statistician, UK ANDREW M SOLOMON

Consultant physician, East and North Hertfordshire NHS Trust, Stevenage, UK

\section{References}

1 Farsani S, Brodovicz K, Soleymanlou N et al. Incidence and prevalence of diabetic ketoacidosis (DKA) among adults with type 1 diabetes mellitus (T1D): a systematic literature review. BMJ Open 2017:7:e016587. 
2 Tikander E, Ranjan A, Schmidt S et al. Diabetic ketoacidosis in a person with insulin pump-treated type 1 diabetes mellitus while following a very low carbohydrate diet - a case report. Arch Clin Med Case Rep 2019:3:418-21.

3 Junichi S, Tatsuhiko U. Insulin pump failure is an important risk factor for diabetic ketoacidosis in pediatric patients with type 1 diabetes. Biomed J Sci \& Tech Res 2018:4:3880-1.

4 Ziegler A, Williams T, Yarid N et al. Fatalities due to failure of continuous subcutaneous insulin infusion devices: a report of six cases. J Forensic Sci 2019;64:275-80.
5 Anstey J, Yassaee A, Solomon A. Clinical outcomes of adult inpatients treated with continuous subcutaneous insulin infusion for diabetes mellitus: a systematic review. Diabet Med 2015;32:1279-88.

Address for correspondence: Dr Andrew Solomon, East and North Hertfordshire NHS Trust, Lister Hospital, Stevenage SG1 4AB, UK.

Email: andrew.solomon@nhs.net

\section{RCP journals now available in PubMed Central}

Both ClinMed and Future Healthcare Journal are now available in PubMed Central, a web-based, free full-text archive of journal literature for all biomedical and life sciences.

Inclusion of the content back to the very first issue of both journals provides readers with greater access to valuable scholarly content and makes finding articles easier. It also means that journal content is now part of a permanent and freely accessible archive, managed by the National Library of Medicine.

FHJ can be accessed at: www.ncbi.nlm.nih.gov/pmc/journals/3619 Clin Med at: www.ncbi.nlm.nih.gov/pmc/journals/2945
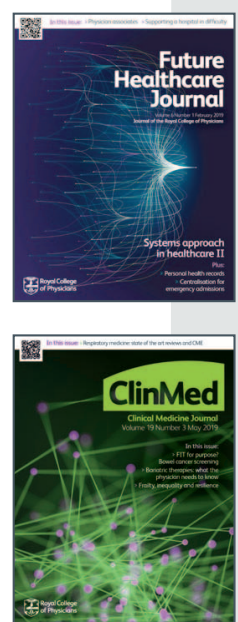